Revista de Economia Política, vol. 42, $n^{\circ}$ 1, pp. 150-171, janeiro-março/2022

\title{
Política monetária no Brasil em tempos de pandemia
}

\author{
Monetary policy in Brazil in pandemic times
}

\author{
CARMEM FEIJÓ* \\ ELIANE CRISTINA ARAÚJO** \\ LUIZ CARLOS BRESSER-PEREIRA***
}

\begin{abstract}
RESUMO: O artigo discute a determinação da inflação no Brasil, sobretudo a partir da grande recessão de 2015-2016, para avaliar a adequação da política de manipulação de taxas de juros para controlar a alta de preços decorrente de pressão permanente de custos. $\mathrm{O}$ ônus de usar a taxa de juros para combater inflação de custo é criar um nível altamente convencional da taxa de juros real, o que, em uma economia financeirizada, beneficia a classe dos rentistas. À luz da macroeconomia pós-keynesiana, a convenção de alta taxa de juros mantém a economia com baixa taxa de crescimento e baixa taxa de investimento, o que no caso da economia brasileira tem resultado em regressão da matriz produtiva e estagnação da produtividade e ambos contribuem para perpetuar as pressões de custo sobre os preços. A análise empírica corrobora a discussão de que a inflação recente teve sua origem em pressões de custos sobre as quais o impacto da taxa de juros para seu controle é limitado. Complementamos a análise empírica testando a resposta à taxa de juros SELIC das variáveis utilizadas para explicar a flutuação dos preços livres e dos preços administrados: índice de preços de commodities, taxa de câmbio e nível de atividade. Conforme esperado, o impacto da alta da taxa de juros valoriza a taxa de câmbio, favorecendo o controle da inflação e reduzindo o nível de atividade, mas não tem impacto no índice de preços das commodities.

PALAVRAS-CHAVE: Inflação de custos; política monetária keynesiana; inflação inercial; economia brasileira.
\end{abstract}

ABSTRACT: The paper discusses the determination of inflation in Brazil, especially after the great recession of 2015-2016, to assess the adequacy of manipulating interest rates to control the rise in prices due to permanent cost pressure. The burden of using the interest rate to fight

\footnotetext{
* Universidade Federal Fluminense - UFF, Niterói/RJ, Brasil. E-mail: cfeijo@gmail.com. Orcid: https:// orcid.org/ 0000-0002-6376-4599.

* Universidade Estadual de Maringá - UFM, Maringá/PR, Brasil. E-mail: elianedearaujo@gmail.com. Orcid: https://orcid.org/0000-0001-5104-2508.

*** Professor emérito da Fundação Getulio Vargas, São Paulo/SP, Brasil. E-mail: bresserpereira@gmail. com. Orcid: https://orcid.org/0000.0001.8679.0557. Submetido: 13/Maio/2021; Aprovado: 15/Julho/2021.
} 
cost inflation is to create a highly conventional level of the real interest rate, which benefits the rentier class in a financialized economy. In the light of the post-Keynesian macroeconomics, a high-interest rate convention keeps the economy with a low growth rate and a low investment rate, which in the case of the Brazilian economy has resulted in a regression in the productive matrix and productivity stagnation, and both contribute to perpetuating cost pressures on prices. The empirical analysis corroborates the discussion about recent inflation having its origin in cost pressures over which the interest rate impact for its control is limited. We complement the empirical analysis by testing the response to the SELIC interest rate of the variables used to explain the fluctuation of market prices and administered prices: commodity price index, exchange rate and activity level. As expected, the impact of an increase in the interest rate appreciates the exchange rate, favouring inflation control and reducing the level of activity but has no impact on the commodity price index.

KEYWORDS: Cost inflation; Keynesian monetary policy; inertial inflation; Brazilian economy.

JEL Classification: E12; E31; E43; E52.

\section{INTRODUÇÃO}

A economia brasileira entrou na pandemia da Covid-19 em 2020 sem ter se recuperado da grande recessão econômica de 2015-2016. Depois da queda acumulada de 6,7\% do PIB durante a recessão, o crescimento de 2017-2019 foi de $4,6 \%$, longe de recompor o nível de produto do período pré-recessão. Apesar da queda registrada em 2020 ter sido menor do que a prevista no início da pandemia $(-4.1 \%)$, pode-se afirmar que a economia brasileira se encontra estagnada desde meados dos anos $2010 .^{1}$

O contexto de estagnação do produto e elevado desemprego vem acompanhado de políticas de austeridade fiscal implementadas desde 2015. Quanto à política monetária, o movimento de queda da taxa básica de juros (SELIC) iniciada em 2016 foi interrompido em março de 2021, quando o IPCA atingiu 6,10\% em 12 meses, valor superior ao teto da meta $(3,75 \%$ com limite de $5,25 \%)$ estabelecida para 2021 , mas, em termos reais, ela se reduzira a $0,7 \%$ aa - um valor muito menor do que aquele ao qual está acostumado o mercado financeiro (média da taxa SELIC descontada a inflação foi de $3,7 \%$ aa no período $2011-2015$ e $2,2 \%$ aa em 2016 -2020, ver Figura 2). O Banco Central reduziu a SELIC de 14,15\% aa em agosto de 2016 para $1,94 \%$ aa em agosto de 2020 até fevereiro de 2021 principalmente porque a economia se mostrava quase estagnada, mas tal redução, como vemos na Figura 1, levou a taxa de juros real a ficar negativa em 2020, fato que contraria as expectativas (e desejos) do mercado financeiro.

\footnotetext{
${ }^{1}$ Sicsu (2019) e Sicsu et al. (2021) argumentam que a economia brasileira está em uma depressão.
} 
Figura 1: Taxa SELIC nominal e real (\%) - 2000-2020

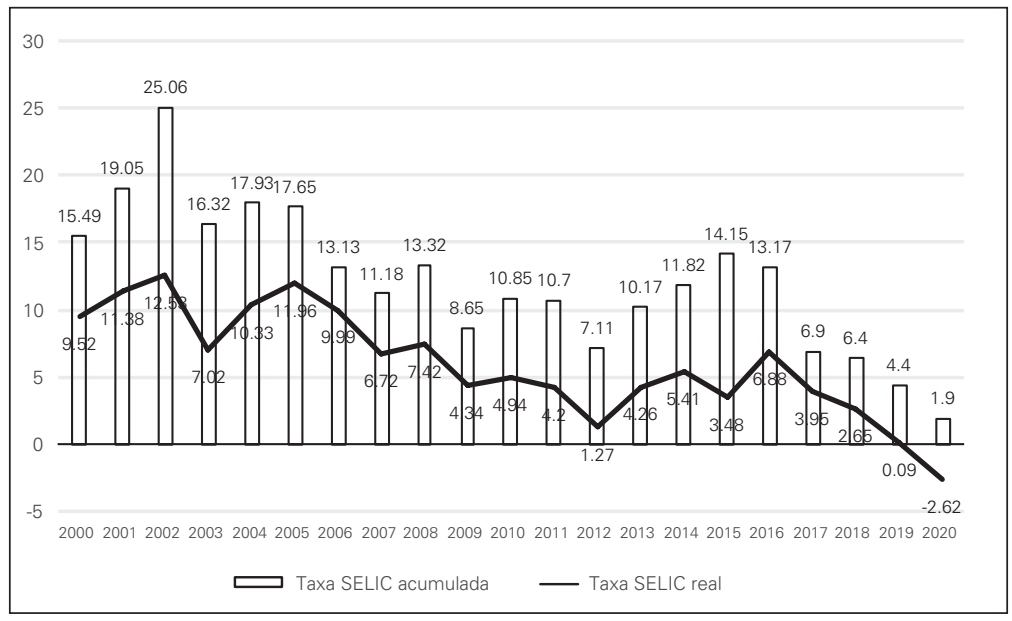

Fonte: BCB (série 4189) e IBGE (IPCA).

A partir do início de 2020 o cenário de pandemia impactou os preços internacionais além de promover elevada desvalorização do real em 2020 e 2021. Mesmo reconhecendo que o aumento da inflação em 2021 teve com uma das principais causas pressões de custo, o comitê de política monetária não tentou reverter o choque primário dos preços e procurou, com o aumento da taxa básica de juros em 0,75 ponto percentual e a sinalização de que a taxa continuaria a aumentar ao longo de 2021, neutralizar os efeitos secundários do choque na taxa de inflação. Conforme explica Barbosa Filho, ${ }^{2}$ se o efeito do choque é considerado temporário, a expectativa de inflação a médio prazo não deve mudar muito. Mas se a expectativa de inflação para um ou dois anos à frente subir muito, como foi a avaliação do comitê de política monetária na reunião de março, então o diagnóstico é de que o choque não é temporário, e a taxa básica de juros deve subir.

O ponto a questionar especificamente na decisão de março é sobre como avaliar a formação de expectativas quando o cenário da pandemia é de incerteza absoluta. Ainda não há um consenso entre os especialistas sobre a duração da pandemia dadas as novas variantes do vírus associadas e a demora no processo de imunização. ${ }^{3} \mathrm{~A}$ decisão do Comitê de Política Monetária tomada em plena pandemia deixa antever o retorno à escalada de taxas de juros elevadas com base na tese de que os agentes econômicos preveem um aumento a longo prazo da inflação.

Ao tomar essa decisão, o Comitê de Política Monetária segue a teoria econômica

\footnotetext{
2 Cf. https://www1.folha.uol.com.br/colunas/nelson-barbosa/2021/03/este-banco-central-merece-umvoto-de-confianca.shtml.

${ }^{3}$ Por outro lado, o cenário de incerteza econômica causada pela pandemia continuará a pressionar os gastos públicos e piorar os indicadores de endividamento público, o que alimenta a narrativa em defesa da política de austeridade fiscal e da política monetária contracionista.
} 
que ensina que, quando o processo inflacionário tem origem no lado da demanda, ele deve ser controlado por meio da adoção de política monetária restritiva, isto é, pelo aumento da taxa de juros que elimine o excesso de demanda agregada. Essa decisão desconsidera pelo menos duas características importantes da economia brasileira que diminuem o impacto de uma alta na taxa de juros sobre o produto: a mudança na estrutura da oferta nas últimas duas décadas dado o avanço acelerado da desindustrialização e a expressiva presença de preços monitorados no índice oficial de inflação (IPCA).

A mudança na estrutura produtiva se caracterizou pela desindustrialização prematura e pela especialização da pauta de exportações em commodities. Ambos os fatores contribuíram para que a inflação no país se tornasse mais dependente da inflação dos nossos parceiros comerciais e dos preços das commodities no mercado internacional. Esse retrocesso de nossa estrutura produtiva tornou, assim, a inflação mais suscetível às pressões de custo advindas do comércio internacional.

Os preços administrados, por sua vez, são basicamente determinados ou influenciados por uma regra de reajuste estabelecida por órgão público. Esse é o caso dos transportes, saúde e cuidados pessoais, habitação, comunicação e outros, que correspondem a mais de $25 \%$ do IPCA. De acordo com o Banco Central do Brasil (2016, p. 13, nota 12), boa parte dos itens que compõem os preços administrados, como energia e combustíveis, é de insumos na produção de outros bens e serviços e, portanto, os impactos ao longo da cadeia produtiva e de distribuição se configuram nos efeitos secundários desses aumentos. Ora, esses preços são pouco sensíveis às condições de oferta e demanda, ou seja, pouco se alteram quando a política monetária se torna tanto mais restritiva quanto mais expansiva. Assim, essa parcela de preços não responde às mudanças na taxa de juros, a política monetária precisa ser ainda mais contracionista para induzir a inflação para a meta estipulada.

Essas duas especificidades aliadas ao momento de incerteza absoluta sobre a pandemia tornam a taxa básica de juros pouco eficiente como instrumento de combate à inflação. No entanto, a política monetária restritiva também pode ser utilizada para debelar processos inflacionários que têm origem pelo lado da oferta. Neste caso, a elevação da taxa de juros não atua sobre as causas que originam a aceleração da inflação, mas procura reduzir os efeitos de choques de custo. Ao reduzir os níveis de atividade e emprego da economia, a política monetária restritiva pode evitar que a elevação nos custos seja repassada em sua totalidade para os preços. O Comitê de Política Monetária sabe disso e por isso procura se justificar com a tese que expectativas de inflação crescentes acelerarão a inflação mesmo que não haja excesso de demanda. Na verdade, a elevação da taxa de juros para reduzir as expectativas de inflação apenas provoca um aumento desnecessário do desemprego e do hiato de produto. No caso brasileiro, no qual os financistas e os consultores financeiros se acostumaram com uma taxa de juros real elevada, as expectativas de aumento significativo da inflação refletem mais um desejo da parte deles que a taxa real de juros se mantenha real, e não a fenômenos reais que tornam crescentes as expectativas de inflação.

Neste artigo nosso objetivo é apresentar um modelo econométrico de determi- 
nação da inflação no Brasil a partir da grande recessão de 2015-2016 para discutir a adequação da política de manipulação da taxa de juros para controlar a alta de preços que tem como origem pressão permanente de custos. O ônus de se utilizar a taxa de juros para o combate a uma inflação de custo é o de criar uma convenção de um nível excessivamente elevado de juros, fato que, numa economia financeirizada, beneficia a classe de rentistas. À luz da macroeconomia pós-keynesiana, uma convenção de juros elevados mantém a economia com baixo ritmo de crescimento e baixa taxa de investimento, o que no caso da economia brasileira tem resultado em retrocesso da matriz produtiva e estagnação da produtividade ao contribuir para perpetuar as pressões de custo sobre os preços e o patamar elevado de juros.

Para analisar os efeitos da taxa de juros sobre a inflação desde 2014 e avaliar criticamente a decisão de elevação da taxa básica de juros em plena pandemia, dividimos este artigo em mais três seções. Inicialmente, recuperamos a teoria de determinação da taxa de juros de Keynes que se contrapõe à teoria de taxa 'natural' de juros segundo a visão monetarista. Em seguida, discutimos como a autonomia na determinação da taxa de juros em economias periféricas financeiramente integradas encontra limites impostos pela estratégia de crescimento com poupança externa (Bresser-Pereira, 2002; Bresser-Pereira e Nakano, 2003). A menor autonomia da política monetária beneficia a classe rentista se o controle da inflação é feito via controle da taxa de juros (Bresser-Pereira e Nakano, 2002). Para concluir a discussão teórica, recuperamos brevemente a teoria pós-keynesiana de determinação de preços pelos custos de produção e a teoria novo-desenvolvimentista da inflação inercial. À luz da teoria monetária de Keynes, o combate à inflação deve utilizar instrumentos de política de acordo com as fontes de pressão sobre os preços. A teoria da inflação inercial, por sua vez, reforça a importância da formação das expectativas no processo inflacionário, mas rejeita a ideia da ortodoxia liberal segundo a qual basta o governo sinalizar uma mudança, por exemplo, na política cambial para que os agentes mudem suas expectativas. Essa crença levou a economia argentina, em 1979, e a economia chilena, em 1981, a grandes crises financeiras. A segunda seção do artigo apresenta a análise empírica que mostra o impacto dos choques de oferta na determinação da inflação dos preços livres e dos preços administrados. As evidências encontradas corroboram a discussão sobre a inflação recente ter sua origem em pressões de custo sobre as quais o impacto da taxa de juros para seu controle é limitado. Complementamos a análise empírica testando a resposta à taxa de juros SELIC das variáveis utilizadas para explicar a flutuação dos preços livres e dos preços administrados: índice de preço das commodities, taxa de câmbio e nível de atividade. Como esperado, o impacto de um aumento na taxa de juros aprecia o câmbio, o que favorece o controle da inflação e reduz o nível de atividade, porém tem impacto nulo sobre o índice de preço das commodities. Uma última seção resume as principais considerações do artigo, apontando que o uso inadequado da taxa de juros para combater uma inflação cujas causas são predominantemente de custos em ambiente de incerteza absoluta como o da pandemia, leva a se questionar sobre a captura da autoridade monetária a interesses de rentistas. 


\section{A DETERMINAÇÃO DA TAXA DE JUROS E A FORMAÇÃO DOS PREÇOS}

Partindo de pressupostos distintos em relação à literatura convencional sobre o papel da política monetária na determinação do nível de produto e renda, a literatura pós-keynesiana identifica as fontes de pressão sobre os preços para desenhar as políticas para o seu controle. Embora a importância da taxa de juros como instrumento de política monetária seja reconhecida, seu uso não é considerado adequado quando a fonte da inflação não é a demanda. Isto porque a taxa de juros é um componente importante na formação dos preços de bens, serviços e de ativos e, portanto, seus efeitos têm impactos duradouros na economia. Ou seja, a moeda não é neutra, nem no curto e nem no longo prazo. No curto prazo, altera os preços relativos daqueles produtos intensivos em juros. Conforme argumenta Hannsgen (2006), quando a política monetária depende da taxa de juros como o principal instrumento de controle da inflação, ela aumenta os preços relativos de bens nos quais o pagamento de juros é um "ingrediente" especialmente importante. No longo prazo, a elevação da taxa de juros desestimula a alocação de recursos em ativos de longa duração, reduzindo o potencial de crescimento da economia. O objetivo desta seção é discutir brevemente a perspectiva analítica de Keynes sobre a taxa de juros, a autonomia da política monetária, e a teoria da inflação inercial que distingue os fatores da inflação em aceleradores, mantenedores e sancionadores.

\section{A teoria da preferência pela liquidez de Keynes, a determinação da taxa de juros 'normal'}

A hipótese da não neutralidade da moeda em Keynes implica que a moeda pode ser retida indefinidamente se a incerteza sobre acontecimentos futuros, captados pelo atributo do prêmio de liquidez, for muito forte. Esse pode ser o caso quando decisões são desapontadas e a preferência dos investidores se move na direção a ativos mais líquidos. A política monetária, ao determinar a taxa de juros nominal de curto prazo, atua sobre o grau de preferência pela liquidez das diferentes classes de ativos, e portanto afeta as escolhas de portfólio e o ritmo de acumulação de ativos de capital físico e de crescimento econômico no longo prazo. ${ }^{4}$ Se o objetivo da política monetária for, por exemplo, manter a economia em pleno emprego, deveria prover liquidez suficiente para manter as taxas de juros nominais e reais em níveis baixos e, assim, estimular a troca de ativos líquidos mantidos na circulação financeira por ativos ilíquidos produzidos na circulação industrial. ${ }^{5}$

\footnotetext{
${ }^{4}$ Segundo Tily (2012, p. 59), a taxa de juros é determinada pela oferta e demanda de ativos nos quais os estoques de riqueza (poupança) podem ser alocados, incluindo a moeda. Conclui que a teoria da preferência pela liquidez é a teoria de Keynes da taxa de juros.

${ }^{5}$ Conforme apontado por Carvalho (2005), a determinação da taxa de juros de curto prazo pelo banco central afeta as taxas de juros de longo prazo por meio de uma curva de rendimento. Segundo o autor, um sistema financeiro suficientemente diversificado em termos de mercados e instituições transmitiria o ajuste da carteira do setor bancário induzido pelas operações de mercado aberto ao segmento de maior
} 
No entanto, Keynes (1936) percebeu que a eficiência da política monetária, ou seja, a capacidade de cumprir seus objetivos, dependeria de sua credibilidade. Nos seus termos, a taxa de juros de curto prazo pode ser facilmente controlada pela autoridade monetária, mas a taxa de longo prazo depende da habilidade da autoridade monetária de induzir um nível para os juros que seja aceito pela 'opinião representativa'. É nesse sentido que Keynes define que “ [...] a taxa de juros é um fenômeno altamente convencional[...]" (p. 203), que deveria estar em um nível que permita o funcionamento da economia próximo ao pleno emprego ao longo do tempo. ${ }^{6}$

Portanto, na teoria monetária de Keynes, o nível da taxa de juros que influencia a retenção de ativos em diferentes graus de prêmio de liquidez deve ser aceito com convicção suficiente pelos detentores de riqueza privada. A responsabilidade do banco central é estabelecer uma convenção sobre o nível "normal" da taxa de juros, que irá ancorar as decisões de carteira dos agentes privados. Diferentemente da visão monetarista convencional, em que a política monetária é o instrumento para o combate a inflação e seria neutra no longo prazo, conforme argumentado por Friedman (1968), na visão de Keynes a política monetária de curto prazo é um poderoso instrumento para determinar a trajetória de crescimento de longo prazo por meio de sua influência na preferência pela liquidez dos agentes econômicos.

\section{Política monetária de Keynes em uma economia aberta e a estratégia de crescer com poupança externa}

Em economias abertas, o grau de autonomia da política monetária é diferenciado pelo grau de conversibilidade de suas moedas e das escolhas de políticas econômicas para alavancar o crescimento. Os modelos macroeconômicos convencionais, baseados na tradição Mundell-Fleming, concluem que em economias pequenas com mobilidade de capitais a autonomia da política monetária é alcançada com um regime de câmbio flutuante. A ligação entre a política monetária e o mercado financeiro internacional é descrita pela equação de paridade descoberta da taxa de juros que estabelece que enquanto a autoridade monetária estiver disposta a deixar a taxa de câmbio suportar o ônus do ajuste, a política monetária buscará autonomia por meio da fixação da taxa de juros nominal ${ }^{7}$ e, dada a taxa de inflação, das taxas

maturidade do mercado. Quanto mais longa a cauda da curva de rendimento, mais eficiente será o mecanismo de transmissão das mudanças na taxa de juros de curto prazo às mudanças na taxa de juros de longo prazo - aquela que importa para as decisões de investimento de longo prazo em ativos fixos bens de capital.

${ }^{6}$ Este é um insight que se opõe à teoria convencional que defende que existe um nível "natural” para a taxa de juros que se supõe ser conhecido pelo mercado. Sob o pressuposto de incerteza não probabilística, mercados futuros completos são inexistentes e, portanto, a determinação de uma taxa de juros de equilíbrio de longo prazo, bem como de um preço de equilíbrio de longo prazo dos ativos, é indeterminada.

${ }^{7}$ Esta conclusão baseia-se na teoria da paridade descoberta de taxas de juros (Carvalho, 2009), que pode ser expressa pela equação $\mathrm{i}=\mathrm{i} *+$ ee $+\Psi$. Em um mundo de livre movimentação de capitais, os juros domésticos i igualam-se à taxa de juros internacional i * mais a expectativa de depreciação da 
de juros reais. Esse raciocínio seria válido apenas se os fluxos de capital internacional, caracterizados na literatura como poupança externa, fossem complementares à poupança interna. Conforme argumenta a teoria novo-desenvolvimentista, há forte evidência de que o excesso de entradas de capital externo em relação à saída implica uma apreciação cambial que tira competitividade das empresas industriais ao deslocar a poupança doméstica e ao promover o aumento do consumo doméstico e não do investimento produtivo. ${ }^{8}$ Ademais, se a economia doméstica adota o regime de metas de inflação, a elevação das taxas de juros nominais pelo banco central resulta em entradas líquidas de capital que apreciam o câmbio - o que ajuda no controle da inflação mas tem efeitos danosos sobre o investimento e o crescimento. ${ }^{9}$ Além disso, dado o diferencial de juros, os ingressos líquidos de capitais e a apreciação de longo prazo da taxa de câmbio continuarão enquanto persistirem os déficits em conta-corrente e a disposição dos mercados financeiros internacionais em financiar o déficit externo. Qualquer reversão de tal percepção favorável afetará severamente a economia, levando inevitavelmente a uma desvalorização súbita e acentuada da moeda.

Assim, a autonomia da política monetária é mais restrita em economias financeiramente integradas sem moeda conversível e que adotam a estratégia de crescimento com endividamento externo. Nesse contexto, as taxas de juros reais tendem a ser mais altas e as taxas de câmbio reais tendem a ser voláteis e valorizadas, ou seja, o nível "normal" convencional da taxa de juros deve ser sistematicamente mais alto quando comparado com as economias desenvolvidas.

\section{A formação de preços e a inflação de custos}

A teoria pós-keynesiana advoga que a política monetária não deve ser o único mecanismo de controle da inflação, pois seu uso pode introduzir graves distorções no processo de formação de preços. Na visão de Keynes, os preços são basicamente determinados pelos custos e, portanto, uma das principais fontes de pressão inflacionária vem do lado da oferta, e não apenas do lado da demanda, conforme assumido pela visão monetarista. ${ }^{10}$ Nesse sentido, a inflação é principalmente um sintoma de pressões de custos e não sua causa.

Essa é a principal razão pela qual o uso da taxa de juros não deve ser o único

taxa de câmbio ee e o prêmio de risco país $\Psi$. Qualquer diferença entre i e i * reflete mudanças em ee e / ou no risco-país. Supondo que não haja mudança no risco-país, a taxa de câmbio deve se mover para compensar os ganhos financeiros dos investidores medidos na mesma moeda.

${ }^{8}$ Para uma visão ampla da teoria novo-desenvolvimentista ver Bresser-Pereira, 2020. Sobre o desestímulo ao investimento e a substituição de poupança interna por externa ao invés desta se somar à primeira ver Bresser e Gala (2006).

${ }^{9}$ Ver, por exemplo, Epstein e Yeldan (2009). Especificamente, para atrair capitais com diferencial elevado de taxa de juros, o qual se torna uma causa de um nível alto de juros como aquele que prevaleceu no Brasil entre 1992 e 2019, ver Bresser-Pereira, Paula e Bruno (2020).

${ }^{10}$ Ver Davidson (1978 e 1994) e Sicsú (2003). 
instrumento de controle da inflação. Keynes não negou que um aumento na taxa de juros pode funcionar para controlar a inflação. No entanto, para ele, esse mecanismo apenas dificulta a passagem do aumento dos custos para os preços finais. $\mathrm{Na}$ verdade, uma política econômica de combate à inflação que atue sobre a demanda agregada pode até agravar o processo inflacionário. De acordo com o princípio da demanda efetiva, a demanda restringida por um aumento na taxa de juros de curto prazo claramente tem efeitos negativos de longo prazo sobre o nível de produto potencial. Este impacto negativo advém do investimento na formação de capital que irá reduzir a oferta agregada e, consequentemente, irá inibir o processo de mudança estrutural que conduz a economia a estágios mais avançados de desenvolvimento tecnológico e maiores ganhos de produtividade. Controlar a inflação de pressão de custos por meio da restrição da demanda agregada perpetuará o aumento dos custos por meio de tendências de feedback inflacionário. ${ }^{11}$ Finalmente, deve-se acrescentar que pressões inflacionárias de diferentes fontes podem ocorrer simultaneamente. Essa é outra forma de dizer que o processo inflacionário é um fenômeno complexo e não deve ser controlado por um único instrumento de política monetária.

\section{Teoria novo-desenvolvimentista e da inflação inercial}

Finalmente, a teoria novo-desenvolvimentista da inflação usa o conceito de inflação inercial para entender por que quando a insuficiência de demanda se verifica a inflação não cai mas se mantém inercialmente no mesmo patamar. Isto acontece porque, na inflação, é preciso distinguir os fatores aceleradores dos mantenedores e dos fatores sancionadores da inflação. ${ }^{12} \mathrm{O}$ fator acelerador da inflação por excelência é o excesso de demanda, mas pode ser também um choque de custo, o fator mantenedor é a inércia, a indexação formal e informal da economia que leva os agentes econômicos a aumentarem seus preços de acordo com a inflação passada que, normalmente, se considera como uma boa expectativa para a inflação que se seguirá. O fator sancionador da inflação é oferta de moeda que é entendida como endógena. Na clássica relação de trocas ela é uma consequência da inflação, não a sua causa como pretendia a teoria monetarista.

Para a teoria inercial da inflação, como para a keynesiana, as expectativas são um fator determinante da inflação. No caso do fator mantenedor, é a inflação imediatamente passada que serve de referência para a expectativa de inflação e para o aumento dos preços. No caso do fator acelerador, quando há excesso de demanda em relação à oferta, os agentes imediatamente formam a expectativa de aumento da inflação e aumentam os preços, mas não têm certeza de quanto deve ser esse

\footnotetext{
${ }^{11}$ Mesmo nos casos em que o aumento da taxa de juros é capaz de promover a estabilidade de preços quando a inflação é um fenômeno puxado pela demanda, a teoria de Keynes apresenta ressalvas. Isso ocorre porque a restrição da demanda agregada tem impactos adversos sobre os níveis de produção e emprego. Assim, há um custo relacionado à manutenção da estabilidade de preços por meio da gestão da taxa de juros: a economia é mantida em um nível de atividade abaixo do seu potencial (Modenesi, 2014).

${ }^{12}$ Ver Bresser-Pereira e Nakano (1983). A teoria já está no título do artigo, "Fatores aceleradores, mantenedores, e sancionadores da inflação”. Hoje essa teoria já está incorporada inclusive nos livros-textos.
} 
aumento - o que os leva a serem cautelosos. Esta teoria, porém, é fortemente crítica da tese monetarista de que basta uma indicação do governo quanto ao ajuste fiscal que está fazendo, ou à âncora cambial que está decidindo adotar para os agentes econômicos, obedientemente, acreditarem e formarem suas expectativas como os economistas monetaristas previram. Os resultados desastrosos dessa tese foram há muito tempo mostrados por Carlos-Diaz Alejandro (1981). A grande crise de 1979 na Argentina e a crise igualmente forte que aconteceu no Chile um pouco depois foi causada pela crença monetarista de que a decisão do governo de baixar gradualmente a correção monetária da taxa de câmbio levaria os agentes econômicos a igualmente baixar sua indexação informal dos preços. Eles naturalmente não agiram como o esperado, houve uma forte valorização das duas moedas locais, e a crise cambial.

\section{O REGIME DE METAS DE INFLAÇÃO NO BRASIL}

A breve apresentação da visão de Keynes e dos pós-keynesianos e da teoria novo-desenvolvimentista (inclusive a teoria da inflação inercial) sobre a taxa de inflação, a determinação da taxa de juros e a autonomia da política monetária para o combate à inflação são nossas referências para a discussão empírica sobre os determinantes dos preços no Brasil no período 2014-2021. Assim, a contribuição empírica deste texto é apresentar evidências sobre o processo inflacionário recente e o efeito da política monetária implementada, interpretando os seus resultados sob outras lentes de análise teórica diferentes da monetarista. Com as evidências encontradas podemos fazer uma avaliação crítica sobre a eficácia da política monetária para o controle de preços no período, levando em conta as especificidades da economia brasileira, o contexto da pandemia e a necessidade de superação da estagnação econômica.

O regime de metas de inflação conforme administrado no Brasil utiliza apenas a taxa de juros SELIC como instrumento de controle de preços. Mesmo o instrumento de forward guidance, que tem sido amplamente utilizado pelo Fed americano desde a crise financeira de 2008, ainda não é praticado no caso brasileiro. ${ }^{13} \mathrm{Assim}$, o regime de metas de inflação no Brasil tem sido administrado de forma bastante conservadora, ${ }^{14}$ e por isso pode-se dizer que cada alta inflacionária, independentemente da fonte de pressão, gera expectativa de que as taxas de juros subirão, redu-

\footnotetext{
${ }^{13}$ Conforme aponta Yellen (2016), forward guidance é uma ferramenta de política monetária usada pelo banco central com o fim de sinalizar a taxa de juros de determinado período e assim guiar a economia de forma que a expectativa seja atendida. Este tem sido um reforço importante ao kit de ferramentas do Banco Central Americano (Federal Reserve - Fed), e tem sido utilizada para fornecer acomodação adicional à política monetária depois que as taxas de juros de curto prazo caíram perto de zero. A forward guidance implicou a orientação estendida de taxas futuras, com o anúncio de que manter as 'taxas objetivo' era manter a taxa de juros de curto prazo mais baixas por mais tempo do que se poderia esperar, pressionando significativamente as taxas de empréstimos de longo prazo. Ver Oreiro et al. (2009) para uma discussão sobre a governança da política monetária no Brasil.

${ }^{14}$ Ver Nassif et al. (2020).
} 
zindo as expectativas sobre o crescimento do produto. ${ }^{15} \mathrm{O}$ compromisso do Banco Central de garantir a convergência da inflação para a meta no ano-calendário via taxa de juros, acaba por produzir uma correlação positiva entre aumentos no nível de preços e a formação das expectativas de política monetária contracionista. ${ }^{16} \mathrm{Na}$ interpretação de Keynes, tal comportamento da autoridade monetária estabelece um nível "normal" de taxa de juros em patamar elevado resultando numa convenção de política econômica que combina baixo crescimento e a alta taxa de juros real e nominal. De fato, o crescimento da economia brasileira tomando o período de 2000-2019, até antes da pandemia, foi de 2,4\% aa e o crescimento da taxa de juros real foi de $6,4 \%$ aa. Tomando o período de 2014-2020, esses percentuais são de $-0,9 \%$ aa e $2,8 \%$ aa, respectivamente. ${ }^{17}$ Essa discussão vai de encontro com os resultados de Bresser et al. (2020), que destacam que a prevalência de altas taxas de juros reais no Brasil por décadas levou à formação de uma coalizão de interesses financeiros-rentista interessada na manutenção de juros elevados e na resultante financeirização pelos ganhos de juros.

A Figura 2 mostra a evolução da inflação (IPCA) e da taxa SELIC real para ilustrar a baixa correlação entre elas. Esta é uma primeira indicação de que taxa real de curto prazo não tem sido, por si só, um canal eficiente de transmissão da política monetária para o controle de preços no Brasil. Isso decorre em parte da presença de preços administrados, os quais, conforme a teoria da inflação inercial, tendem a manter o nível de inflação independentemente da demanda e fazem com que as mudanças nas taxas de juros tenham efeito limitado sobre a queda do nível de preços no Brasil. Ou seja, quando o Banco Central do Brasil busca convergir a taxa de inflação real para a meta, ele deve aumentar excessivamente a taxa de juros básica de curto prazo para compensar os preços menos sensíveis a mudanças nas taxas de juros reais.

A Figura 2 mostra também que em torno de 2010 houve uma mudança na política de juros do Banco Central que abandonou a política de elevado nível de juros e passou a definir uma taxa básica de juros inferior à inflação (taxa média real de juros de 2000-2010 foi de 8,7\% aa e caiu para 3,7\% aa de 2011-2015). Essa política foi revertida em 2015, mas se manifestou novamente a partir de 2016 e resultou em substancial queda da taxa de juros real. Ao voltar a aumentar a taxa SELIC em 2021, o Banco Central afirmou que a expectativa de inflação para os dois próximos anos é alta e que já é hora de iniciar "a normalização da taxa de

\footnotetext{
${ }^{15}$ No caso do Brasil, considerando a contração da economia em 2020 e 2021 e as incertezas em relação à evolução da pandemia, não seria o caso de um forward guidance na direção de manter a queda nas taxas de juros? Ademais, o aumento na taxa de juros afeta diretamente a dívida pública, cujas tentativas de controle recaem basicamente sobre o corte de despesas do governo.

${ }^{16}$ Ver Libânio (2004).

17 Araújo et al. (2017) discutem que após a adoção do Regime de Metas de Inflação em 1999, não somente as taxas de crescimento foram baixas e instáveis, como vários indicadores macroeconômicos domésticos se deterioraram e/ou ingressaram em uma trajetória preocupante desde então. Os autores apresentam evidências históricas e empíricas que, embora as causas dessa performance sejam variadas e complexas, certamente as instituições monetárias desempenharam um papel central na sua explicação.
} 
juros”. O que, porém, significa essa normalização não está claro. Se o COPOM usa o conceito de taxa de juros normal, devia informar qual é ela. Cerca de 1 por cento acima da taxa de juros média dos grandes bancos centrais? Ou o quê?

Figura 2: Taxa SELIC anualizada real, variação anual do IPCA

e média da taxa SELIC real para períodos escolhidos (\%) - 2000-2020

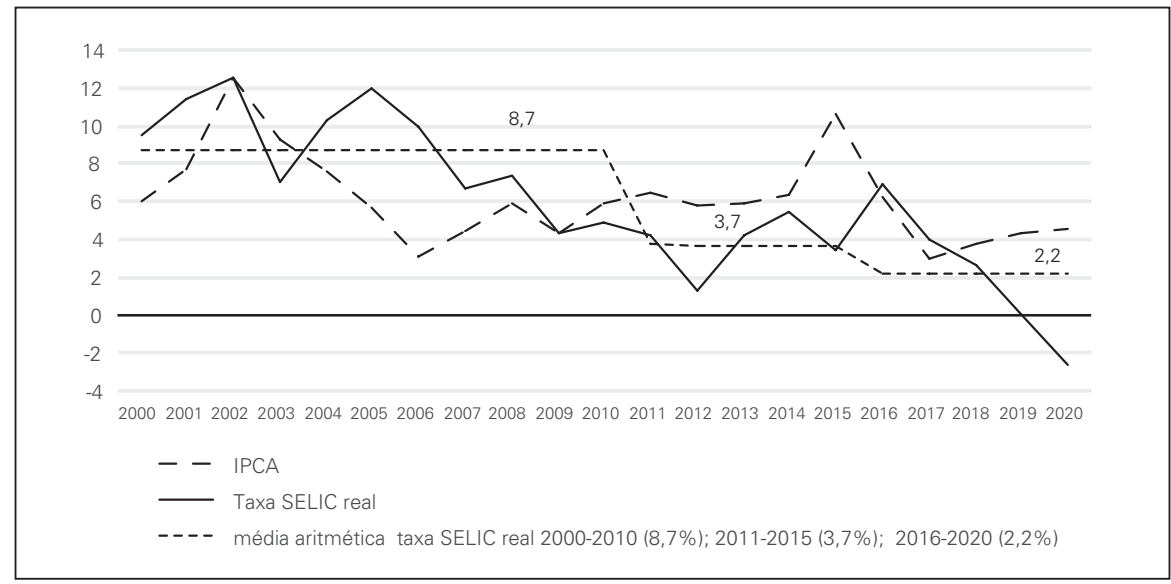

Fonte: IBGE e BCB (série 4189 descontada a inflação- IPCA).

A Figura 3 mostra a evolução dos preços livres e dos preços administrados desde 2000 até o primeiro trimestre de 2021. Apesar de a média de variação mensal dos preços dos dois grupos serem próximas $(0,53 \%$ e $0,59 \%$ para os preços livres e administrados, respectivamente), o mesmo não se observa em termos do desvio padrão: 0,75 e 1,60 respectivamente. O coeficiente de correlação entre as séries, de 0,27 , também sinaliza na direção da inadequação do uso de um único instrumento para o controle dos preços cujo comportamento segue estímulos muito diferenciados.

Figura 3: IPCA Preços livres e IPCA preços administrados: variação percentual no mês - 2000-2021

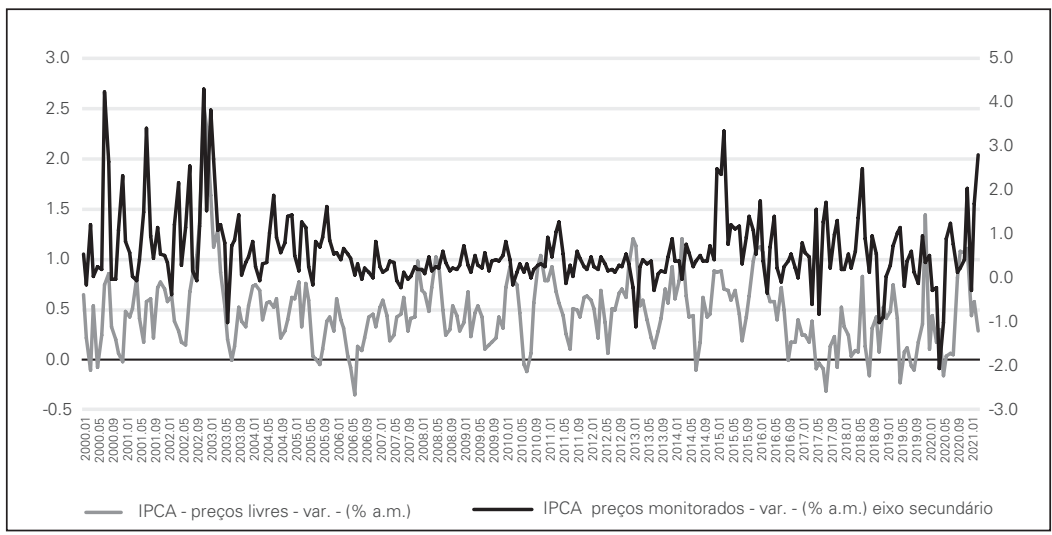

Fonte: Ipeadata. 


\section{INVESTIGAÇÃO EMPÍRICA SOBRE A DETERMINAÇÃO DOS PREÇOS NO BRASIL NO PERÍODO 2014-2021}

Para avançar na discussão sobre a relação da taxa básica de juros e o comportamento dos preços, no exercício econométrico a seguir estimaremos os determinantes dos preços livres e dos preços administrados na economia brasileira no período de 2014 a 2021 e avaliaremos os efeitos de um aumento na taxa de juros SELIC, da taxa de câmbio, do nível de atividade e do índice de preços de commodities sobre as equações dos preços. Nossa hipótese é que os preços livres e os administrados reagem de forma diferente aos impactos das pressões de custo (taxa de juros, taxa de câmbio e preço das commodities) e a pressão de demanda (nível de atividade).

A análise da determinação de preços é realizada com base em um modelo em que a inflação depende de três fatores: i) o nível de atividade econômica, medida pela produção industrial; ii) a taxa de câmbio R \$/US\$ e iii) o índice de preços de commodities. Além disso, é incluída a taxa de juros SELIC, que é o instrumento de política monetária utilizada no controle de preços, bem como a decomposição dos preços em preços livres e administrados. A descrição das variáveis, suas fontes e acrônimos estão dispostos no Quadro 1.

Quadro 1: Séries utilizadas na pesquisa

\begin{tabular}{c|l|c}
\hline Nome das Séries & \multicolumn{1}{|c}{ Descrição das séries } & Fonte \\
\hline TC & $\begin{array}{l}\text { Taxa de câmbio - R\$ / US\$ - comercial } \\
\text { (venda) }\end{array}$ & $\begin{array}{c}\text { Banco Central } \\
\text { do Brasil (BCB) }\end{array}$ \\
\hline SELIC & $\begin{array}{l}\text { Taxa de juros - Over/Selic - (\% a.a.) }- \\
\text { anualizada }\end{array}$ & BCB \\
\hline AE & $\begin{array}{l}\text { Produção industrial - indústria geral - } \\
\text { dessazonalizada }\end{array}$ & BCB \\
\hline IC & Índice de preços de commodities \\
\hline LIV & $\begin{array}{l}\text { Preços - IPCA - preços livres - var. }-(\% \\
\text { a.m.) }\end{array}$ & $\begin{array}{l}\text { Breços - IPCA - preços monitorados - } \\
\text { var. }-(\% \text { a.m.) }\end{array}$ \\
\hline ADM & BCB \\
\hline
\end{tabular}

Fonte: Elaboração própria.

A metodologia empírica consiste na utilização dos modelos de Vetores Autorregressivos (VAR). ${ }^{18}$ Esses modelos permitem que sejam analisadas simulações de choques nas variáveis incluídas na análise sobre o comportamento de nossa variável

\footnotetext{
${ }^{18}$ Mais informações sobre esta metodologia podem ser encontradas em Enders (2014) e Hamilton (1994).
} 
de interesse, os preços livres e os preços administrados. O objetivo, neste caso, é identificar como a inflação de preços livres e administrados se comporta diante dos impulsos acumulados nas variáveis explicativas incluídas no sistema. Os modelos VAR são sempre utilizados quando há a suspeita de viés de endogeneidade, isto é, ao mesmo tempo que a taxa de juros SELIC é influenciada pelo conjunto de variáveis explicativas, ela também afeta essas variáveis.

Às séries do modelo foram aplicados testes de raiz unitária a fim de avaliar se elas seguem ou não um processo estocástico estacionário. A Tabela 1 mostra os resultados do Teste de Dickey-Fuller Aumentado (ADF), proposto por Said e Dickey (1984), com a hipótese nula (H0) de que a variável testada possui raiz unitária (é não estacionária).

Tabela 1: Resultados do teste ADF

\begin{tabular}{|c|c|r|r|r|r|r|r|}
\hline & \multicolumn{7}{|c|}{ Em nível } \\
\hline & & \multicolumn{1}{c|}{ LOGADM } & \multicolumn{1}{c|}{ LOGAE } & \multicolumn{1}{c|}{ LOGIC } & \multicolumn{1}{c|}{ LOGLIV } & \multicolumn{1}{c|}{ LOGSELIC } & \multicolumn{1}{c|}{ LOGTC } \\
\hline c & t-Statistic & $-74,594$ & $-21,877$ & 0.7215 & $-58,223$ & -0.1334 & 0.0122 \\
\hline & Prob. & 0.000 & 0.2118 & 0.9922 & 0.000 & 0.9425 & 0.9573 \\
\hline c, t & t-Statistic & $-7,497$ & $-35,545$ & $-22,431$ & $-60,669$ & $-16,603$ & $-27,774$ \\
\hline & Prob. & 0.000 & 0.0378 & 0.4616 & 0.000 & 0.7632 & 0.2083 \\
\hline & t-Statistic & $-56,184$ & -0.3251 & 28,678 & -0.8028 & -0.984 & 19,196 \\
\hline & Prob. & 0.000 & 0.5666 & 0.999 & 0.3664 & 0.2899 & 0.9868 \\
\hline & & & & Em diferença & & \\
\hline & & d(LOGADM) & d(LOGAE) & d(LOGIC) & d(LOGLIV) & d(LOGSELIC) & d(LOGTC) \\
\hline c & t-Statistic & $-120,825$ & $-113,883$ & $-89,526$ & $-87,894$ & $-3,733$ & $-121,049$ \\
\hline & Prob. & 0.000 & 0.000 & 0.000 & 0.000 & 0.005 & 0.000 \\
\hline c, t & t-Statistic & $-120,474$ & $-113,509$ & $-89,987$ & $-87,526$ & $-42,608$ & $-121,105$ \\
\hline & Prob. & 0.000 & 0.000 & 0.000 & 0.000 & 0.005 & 0.000 \\
\hline & t-Statistic & $-121,224$ & $-114,251$ & $-85,522$ & $-88,302$ & $-36,035$ & $-117,394$ \\
\hline & Prob. & 0.000 & 0.000 & 0.000 & 0.000 & 0.000 & 0.000 \\
\hline
\end{tabular}

Fonte: Elaboração própria.

Para as séries em nível, a estatística t calculada não é superior ao valor crítico tabelado, portanto, não podemos rejeitar a hipótese nula de que as séries AE, IC, SELIC e TC são não estacionárias a um nível de significância de 5\%. Já as variáveis LIV e ADM podem ser consideradas estacionárias em nível, pois a estatística t calculada é superior ao valor crítico tabelado.

É possível diferenciar as séries não estacionárias tantas vezes quantas forem necessárias e realizar o teste de raiz unitária para saber quando ela se torna estacionária, encontrando, assim, a sua ordem de integração. A Tabela 1 mostra também os resultados do teste ADF para a primeira diferença das séries. As estatísticas $t$ 
calculadas permitem rejeitar a hipótese nula, indicando que as séries são estacionárias na primeira diferença e, portanto, integradas de primeira ordem, I (1).

Esses resultados são confirmados pelo teste Phillips (1987) na Tabela 2, cuja hipótese nula também é de que a variável possui uma raiz unitária.

Tabela 2: Resultados do teste PP

\begin{tabular}{|r|l|r|r|r|r|r|r|r|}
\hline & \multicolumn{7}{|c|}{ Em nível } \\
\hline & & \multicolumn{1}{|c|}{ LOGADM } & \multicolumn{1}{c|}{ LOGAE } & \multicolumn{1}{c|}{ LOGIC } & \multicolumn{1}{c|}{ LOGLIV } & \multicolumn{1}{c|}{ LOGSELIC } & \multicolumn{1}{c|}{ LOGTC } \\
\hline c & t-Statistic & $-76,012$ & $-19,203$ & 0.7215 & $-57,701$ & 12,026 & 0.0548 \\
\hline & Prob. & 0.000 & 0.3222 & 0.9922 & 0.000 & 0.9981 & 0.961 \\
\hline c, t & t-Statistic & $-76,373$ & $-37,124$ & $-18,354$ & $-61,006$ & -0.2039 & $-2,853$ \\
\hline & Prob. & 0.000 & 0.0248 & 0.682 & 0.000 & 0.9924 & 0.1814 \\
\hline & t-Statistic & $-60,701$ & -0.4877 & 28,678 & $-32,005$ & $-10,923$ & 19,196 \\
\hline & Prob. & 0.000 & 0.503 & 0.999 & 0.0015 & 0.2479 & 0.9868 \\
\hline & & & \multicolumn{7}{|c|}{ Em diferença } & & \\
\hline c & & t-Statistic & $-234,632$ & $-127,005$ & $-88,704$ & $-211,808$ & $-3,657$ & $-121,068$ \\
\hline & Prob. & 0.000 & 0.000 & 0.000 & 0.000 & 0.006 & 0.000 \\
\hline c, t & t-Statistic & $-23,377$ & $-126,568$ & $-89,205$ & $-211,581$ & $-42,476$ & $-12,112$ \\
\hline & Prob. & 0.000 & 0.000 & 0.000 & 0.000 & 0.005 & 0.000 \\
\hline & t-Statistic & $-227,049$ & $-126,492$ & $-85,782$ & $-212,867$ & $-35,088$ & $-117,398$ \\
\hline & Prob. & 0.000 & 0.000 & 0.000 & 0.000 & 0.001 & 0.000 \\
\hline
\end{tabular}

Fonte: Elaboração propria

Tendo em vista os resultados dos testes de raiz unitária ADF e PP, o modelo VAR utiliza as variáveis AE, IC, SELIC, TC em diferença e as variáveis ADM e LIV em nível. Assim, a estratégia empírica da pesquisa é a estimação de um modelo VAR com as variáveis não estacionárias em diferença (AE, IC, SELIC, TC) e as variáveis estacionárias em nível (ADM e LIV).

O modelo VAR foi estimado com três defasagens, que garantiram a robustez dos resíduos do modelo. A ordem das variáveis foi a seguinte: SELIC, IC, AE, ADM, LIV e TC, valendo destacar que diferentes ordenações foram utilizadas e isso não alterou o formato das funções impulso-resposta.

Os coeficientes dos modelos VAR não são diretamente interpretados, visto que a existência de multicolinearidade os torna, na maioria das vezes, não significativos estatisticamente. Assim, no presente estudo, as análises são feitas a partir das funções impulso-resposta. Estas permitem captar o efeito dinâmico de um choque exógeno sobre as variáveis do modelo em um determinado horizonte de tempo. Além disso, por meio desse método é possível averiguar o tempo em que os efeitos de um 
choque sobre determinada variável são dissipados e a intensidade das respostas em consequência dos choques.

Inicialmente a investigação trata dos determinantes da inflação, assim serão analisadas as respostas dos preços livres e dos preços administrados a choques na taxa de câmbio (TC), atividade econômica (AE) e índice de preços de commodities (IC), conforme as Figuras 4 e 5.

Na Figura 4, no quadrante superior esquerdo, observa-se os efeitos de um choque na taxa SELIC sobre os preços livres, os quais são reduzidos em decorrência de uma elevação dessa taxa. Nos demais quadrantes, um choque positivo na taxa de câmbio (quadrante superior direito), no índice de preços de commodities (quadrante inferior esquerdo) e na atividade econômica (quadrante inferior direito) implica aumento nos preços livres, efeito que se estende de 6 a 8 meses.

Em consonância com esses resultados vale resgatar as conclusões de Modenesi e Araújo (2013) que encontram evidências de que a resposta da inflação a um aumento no nível de atividade econômica medido pela produção industrial foi praticamente desprezível entre 1999 e 2010, enquanto o efeito de aumentos na taxa de câmbio sobre a inflação é altamente significativo. Ao comparar os dois efeitos, os autores encontraram que desvalorizações cambiais eram mais significativas para explicar a elevação na inflação do que aumentos na atividade econômica.

Figura 4: Respostas dos preços livres a choques na taxa de câmbio, atividade econômica e índice de preços de commodities

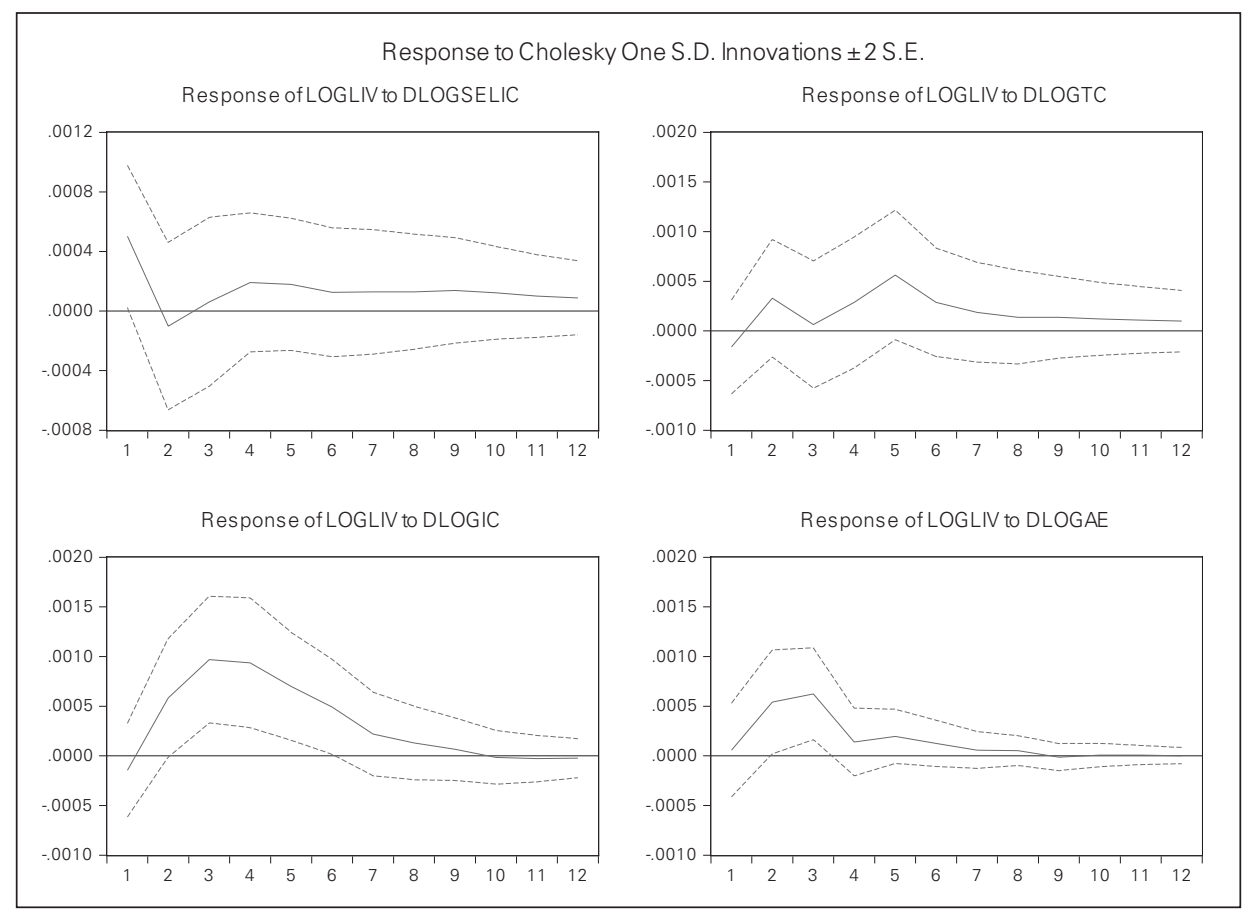

Fonte: Elaboração própria com base nos dados da pesquisa. 
Figura 5: Resposta dos preços administrados a choques na taxa de câmbio, atividade econômica e índice de preços de commodities

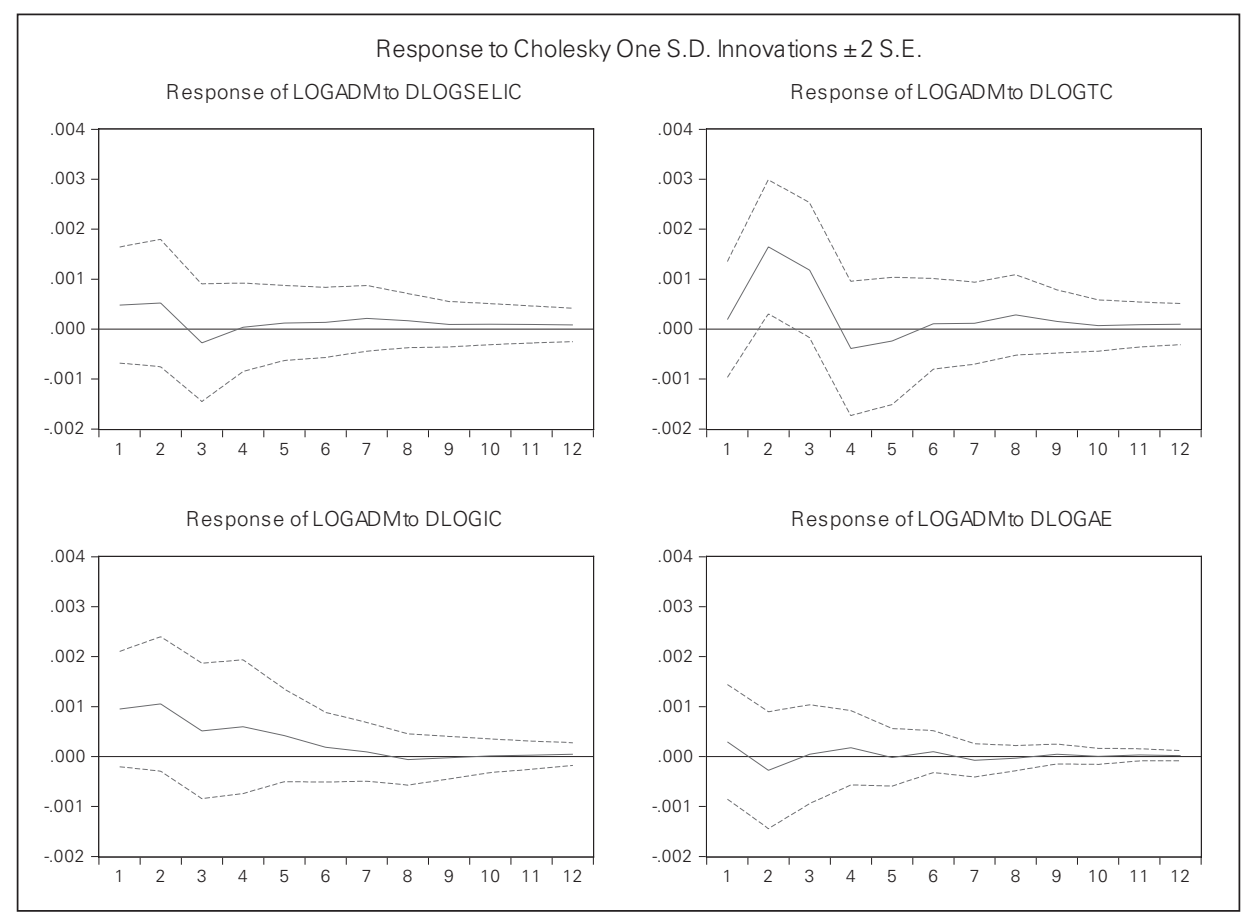

Fonte: Elaboração própria com base nos dados da pesquisa.

A Figura 5 mostra a resposta dos preços administrados a um choque na taxa SELIC (quadrante superior esquerdo), na taxa de câmbio (quadrante superior direito), no índice de preços de commodities (quadrante inferior esquerdo) e na atividade econômica (quadrante inferior direito). Pode-se constatar que as variáveis que mais contribuem para a elevação dos preços administrados são a taxa de câmbio e o índice de preços de commodities, enquanto a atividade econômica e a taxa SELIC praticamente não influenciam mudanças nos preços administrados. É preciso, porém, assinalar que a SELIC tem um efeito indireto sobre a taxa de câmbio na medida em que o diferencial de juros, que aumenta quando o Banco Central aumenta a taxa SELIC, atrai capitais externos e aprecia a moeda nacional. ${ }^{19}$

A partir desses resultados, algumas constatações podem ser feitas. A primeira delas é que um aspecto que limita o funcionamento dos mecanismos de transmissão da política monetária, fazendo com que as mudanças na taxa de juros tenham efeitos limitados sobre a queda dos preços, é a existência de preços administrados. Sicsú

\footnotetext{
${ }^{19}$ Vale ressaltar que diversos autores já comprovaram empiricamente a importância da taxa de câmbio na determinação dos preços, no período posterior a implantação do Plano Real, podendo-se desatacar, por exemplo, Belaisch (2003), Minella et al. (2002, 2003), Araújo e Modenesi (2010) e Araújo et al. (2017).
} 
e Oliveira (2003), por exemplo, sugerem que os preços administrados são pouco sensíveis às condições de oferta e demanda porque são estabelecidos por contrato ou por órgão público, não se alterando perante mudanças na política monetária. Como no Brasil cerca de $26 \%$ do IPCA é composto pelos preços administrados, a política monetária precisa ser ainda mais contracionista para induzir a inflação para a meta estipulada, tendo em vista que essa parcela de preços não responde às mudanças na taxa de juros.

A segunda constatação é referente aos efeitos da taxa de câmbio e do índice de preços de commodities sobre os preços livres e os administrados. Desde a década de 1990, no Brasil, mudanças na estrutura produtiva se caracterizaram pela desindustrialização prematura e pela especialização da pauta de exportações em commodities. Ambos os fatores contribuem para que a inflação do país seja mais dependente da inflação de seus principais parceiros comerciais, além de sofrer maior influência dos preços das commodities no mercado internacional. Esse retrocesso na estrutura produtiva deixa o país mais suscetível à pressões de custo advindas do comércio internacional, o que é corroborado pelas Figuras 4 e 5 que comprovam o importante efeito da taxa de câmbio e do índice de preços de commodities sobre preços livres e administrados.

Por fim, é interessante analisar também como as variáveis que sofreram choques nas figuras anteriores (taxa de câmbio, atividade econômica e índice de preços de commodities) respondem a variações no instrumento de política monetária, a taxa SELIC. A Figura 6 ilustra esses resultados.

Figura 6: Resposta da taxa de câmbio, atividade econômica e índice de preços a um choque positivo na taxa de juros

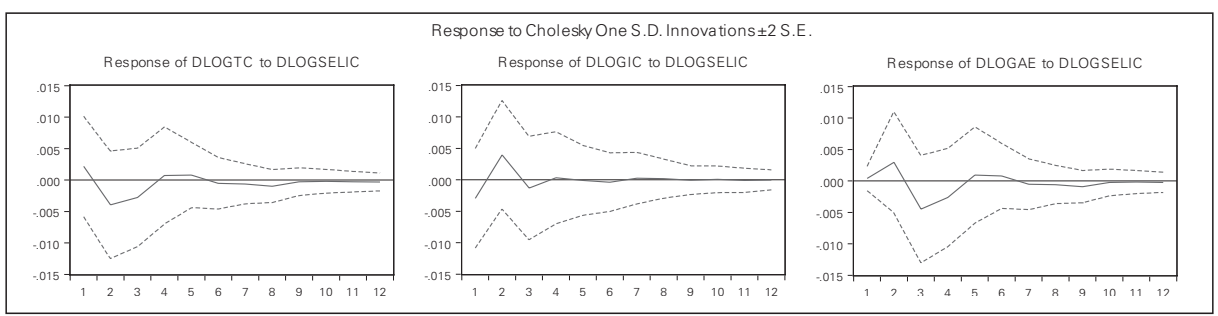

Fonte: Elaboração própria com base nos dados da pesquisa.

Como já era esperando, os efeitos de uma elevação na taxa SELIC sobre o índice de preços de commodities (gráfico do centro) são praticamente insignificantes. Assim, quando a inflação é alterada por choques nos preços das commodities, elevações na taxa SELIC não são eficazes para trazer estes preços para baixo. Esses resultados reforçam a discussão de que as especificidades de uma estrutura de oferta subordinada crescentemente a potenciais pressões de custos externos fazem com que as mudanças na taxa básica de juros com vistas a administrar o nível de inflação tenham efeitos limitados sobre a queda dos preços. O resultado de elevações da taxa básica de juros para combater a inflação é apenas indireto, via apreciação da taxa de câmbio, mas implica o aumento da taxa de sacrifício, em termos da perda do produto e do emprego, causado duplamente pelo aumento da taxa de 
juros e a perda de competitividade da indústria causada pela apreciação cambial e pelo aumento do nível da taxa de juros. Em outras palavras, aumentos na taxa de juros apreciam a taxa de câmbio (gráfico à esquerda) e contribuíram, ao longo do período estudado, para manter os preços sob controle. Já o efeito direto de um aumento dos juros sobre o nível de atividade é, claramente, negativo. Em resposta a um choque da taxa SELIC, o nível de atividade se reduz, confirmando que uma política de elevação da taxa de juros para conter a elevação nos preços impõe um custo imediato para a economia causado pela queda de demanda, e um custo de médio prazo pela perda de competitividade da indústria.

\section{CONSIDERAÇÕES FINAIS}

Desde 1999 a política monetária no Brasil segue o regime de metas de inflação com um único objetivo de alcançar a estabilidade de preços e utilizando como único instrumento para atingir a meta a taxa básica de juros SELIC. Em 22 anos que tem sido praticado, em apenas 7 a inflação ficou dentro da meta estabelecida, sinalizando a baixa eficácia da política. Ademais, como mostrado por Modenesi e Araújo (2013), os mecanismos de transmissão da política monetária sob o regime de metas de inflação são muito falhos, sendo o mais eficaz a taxa de câmbio. Tal resultado, constatado também em outras economias em desenvolvimento, introduz um viés importante na administração da política monetária no sentido de ser tolerante com movimentos de apreciação da taxa real de câmbio pelo efeito positivo sobre o controle da inflação. Como amplamente debatido na literatura novo-desenvolvimentista, a manutenção de elevado nível de taxa de juros para atrair poupança externa, distorce os preços macroeconômicos básicos, dentre eles a taxa de câmbio, que tende a se apreciar e permanecer apreciada por longos períodos não apenas devido à doença holandesa, mas também às entradas líquidas de capital causadas por um diferencial de juros elevado. Esta é uma das principais causas do processo de desindustrialização observado na economia brasileira, o que reduz nosso potencial de crescimento e aumenta a vulnerabilidade a choques de oferta.

Sob a hipótese de não neutralidade da moeda no longo prazo, vimos que a literatura pós-keynesiana e a teoria da inflação inercial apresentam argumentos sólidos para advogar que a taxa de juros não seria o melhor instrumento para o controle da inflação, tendo em vista que é preciso distinguir as causas que mantêm das causas que aceleram a taxa de inflação: o fator que mantém a taxa de inflação é a inércia inflacionária, a indexação formal e informal dos preços; os que mantêm são as pressões de custo e, menos frequentemente, a condição de excesso de demanda em relação à oferta agregada. Além disso, é preciso considerar que taxas de juros elevadas afetam a alocação de recursos penalizando os setores com insumos intensivos em juros. A política de combate à inflação apoiada no instrumento dos juros quando as causas não são pressão de demanda leva a uma convenção de nível de taxa de juros 'normal' muito elevada, afetando negativamente o investimento produtivo e, consequentemente, reduzindo o potencial de crescimento a longo pra- 
zo. Ao substituir a noção de taxa natural de juros (tão cara à teoria monetarista da moeda) pela noção de taxa 'convencional' de juros, a teoria pós-keynesiana e a teoria inercial ampliam o entendimento sobre os efeitos da política monetária que vão além do controle de preços no curto prazo e impacta de forma duradoura o nível de atividade. A busca de credibilidade da política monetária baseada em regra rígida, pode, ademais, levar à captura do banco central pelos interesses do setor financeiro, aumentando a concentração de renda e riqueza. Essa característica é mais forte em economias financeiramente integradas com moeda não conversível e que adotam a estratégia de crescer com poupança externa, como o caso da economia brasileira. Para Keynes, a política monetária é um poderoso instrumento para levar a economia ao pleno emprego e portanto, políticas de combate à inflação deveriam adotar instrumentos observando as causas do fenômeno. Uma integração financeira assimétrica leva a uma redução do espaço de política para a implementação de estratégias de desenvolvimento econômico e geração de emprego.

A análise empírica sobre adequação da taxa de juros para o controle da inflação se concentrou no período 2014-2021 para captar o efeito da recessão (2015-2016) e da pandemia (2020-1 ${ }^{\circ}$ trimestre de 2021) da política do Banco Central do Brasil. No nosso entendimento, o argumento para elevação da taxa básica de juros quando as incertezas sobre a evolução da pandemia são muito grandes sinalizam para a captura da política monetária pelo interesse de rentistas..$^{20}$

Ou seja, a formação de expectativas de inflação em um contexto de incerteza absoluta sobre a evolução da pandemia não deveria ser considerado um guia confiável para justificar a elevação da taxa de juros na pandemia. Os testes empíricos mostraram que a inflação de preços administrados não responde à taxa de juros. Quanto à inflação de preços livres, os testes empíricos confirmaram a relevância dos choques de custo (índice do preço das commodities e taxa de câmbio) sobre sua evolução. Por fim, o teste econométrico aplicado para avaliar qual a eficácia da taxa de juros para o controle das variáveis que impactaram a inflação de preços livres e administrados mostrou que o impacto da taxa de juros SELIC sobre o índice de preço das commodities é nulo, e é negativo sobre a taxa de câmbio (provoca uma leve apreciação) e sobre o nível de atividade.

\section{REFERÊNCIAS BIBLIOGRÁFICAS}

Araújo, E. C; Araújo, E L; Ferrari Filho, F.(2017). Monetary Institutions and Macroeconomic Performance in Brazil after the Global Financial Crisis of 2007/2008. In: Arestis, Philip; Baltar, C; Pra-

\footnotetext{
${ }^{20}$ Vale registrar que André Lara Resende, em recente artigo (Valor, 1/4/2021) estimou que o impacto fiscal sobre a dívida pública brasileira da alta na taxa SELIC na reunião do Comitê de Política Monetária de março de 2021 e a sinalização de que a taxa continuaria a subir ao longo de 2021 equivale a uma transferência de renda do Estado para o sistema financeiro e os detentores de dívida pública. Nas palavras do autor: 'O impacto fiscal de uma alta no custo da dívida é enorme. Uma elevação de $2 \%$ para $6 \%$, numa dívida de $90 \%$ do PIB, equivale a 3,6\% do PIB ao ano (p. 8/13).
} 
tes, D. (eds.). The Brazilian Economy since the Great Financial Crisis of 2007/2008, 1a. Edição, Londres, Palgrave Macmillan, v. 1, p. 41-68.

Araújo, E.; Modenesi, A. M. (2010) "A Importância do Setor Externo na Evolução do IPCA (19992010): uma análise com base em um modelo SVAR.”XXVIII Encontro Nacional de Economia, Salvador.

Banco Central do Brasil (2016). Preços administrados, Série Perguntas Mais Frequentes.

Belaisch, A. (2003), Exchange rate pass-through in Brazil. IMF, Working Papers, no 141.

Bresser-Pereira, Luiz Carlos (2002) "Brazil's quasi-stagnation and the growth cum foreign savings strategy”, International Journal of Political Economy 32(4) Winter 2002-3: 76-102. Print ISSN: 0891-1916.

Bresser-Pereira L.C. (2020). New Developmentalism: development macroeconomics for middle-income countries, Cambridge Journal of Economics, vol. 44, n 3, p.629-646.

Bresser-Pereira, L.C.; Gala, P. (2007). Por que a poupança externa não promove o crescimento, Revista de Economia Política 27 (1): janeiro, p. 3-19. http://www.rep.org.br/PDF/105-1.PDF.

Bresser-Pereira, L.C.; Paula, L.F.; Bruno, M. (2020). Financialization, coalition of interests and interest rates in Brazil, Revue de la Régulation vol. 27 (2020): 1/21-31/. DOI: 10.4000/regulation.16636

Bresser-Pereira, L.C. e Nakano, Y. (1983 [1984]). Fatores aceleradores, mantenedores e sancionadores da inflação, Anais do X Encontro Nacional de Economia, Belém, ANPEC, dezembro 1983. Reproduzido em Revista de Economia Política 4 (1) janeiro 1984: 5-21, e em Bresser-Pereira e Nakano (1984) Inflação e Recessão: p. 56-75.Bresser-Pereira, L.C. e Nakano, Y. (2002). Uma estratégia de desenvolvimento com estabilidade, Brazilian Journal of Political Economy, vol. 22, n. 3-87, p.146-177.

Bresser-Pereira, L.C. e Nakano, Y. (2003). Economic growth with foreign savings?, Brazilian Journal of Political Economy, vol. 23, n. 2, p. 3-27.

Carvalho, F. J. C. (2005). Uma contribuição ao debate em torno da eficácia da política monetária e algumas implicações para o caso do Brasil. Brazilian Journal of Political Economy, 25 (4), p. 323-336.

Carvalho, F. J. C. (2009). The accumulation of international reserves as a defensive strategy: reasons and limitations of "self-insurance". In, J. Stiglitz, S. Griffith-Jones e J.A. Ocampo J A (eds). Financial markets reform. New York: Oxford University Press, p. 269-286.

Davidson, P. (1994). Post Keynesian Macroeconomic Theory. Cheltenhan: Edward Elgar.

Davidson, P. (1978). Money and the Real World. London: Macmillan.

Diaz-Alejandro, C. (1981). Southern Cone stabilization plans, in W. Cline \& S. Weintraub, (eds). Economic Stabilization in Developing Countries, Washington: The Brookings Institution, p. 119-148.

Enders, W. (2014). Applied econometric time series. Wiley Series in Probability and Statistics. 4a. Edição.

Epstein, G; Yeldan, A. E (eds). (2009). Beyond Inflation Targeting: assessing the impacts and policies alternatives, Cheltenham (UK), Edward Elgar.

Friedman, M. (1968). The role of monetary policy. American Economic Review, 58, p. 1-17.

Hamilton, J. (1994). Time series analysis, Princeton University Press.

Hannsgen, G. (2006). The transmission mechanism of monetary policy: a critical review, in P. Arestis, e M. Sawyer (eds), A handbook of alternative monetary economics. Cheltenham (UK): Edward Elgar.

Keynes, J M. (1936). The General Theory of Employment, Interest and Money. London: Macmillan.

Libânio, G. A. (2004). Temas de política monetária: uma perspectiva pós-Keynesiana, Texto para Discussão no. 229, CEDEPLAR: http://www.cedeplar.ufmg.br/pesquisas/td/TD\%20229.pdf.

Minella, A.; Correa, A. S. (2005). "Mecanismos não-lineares de repasse cambial: um modelo de Curva de Phillips com Threshold para o Brasil”. Anais do XXXIII Encontro Nacional de Economia.

Modenesi, A. (2014). Política Monetária e Combate à Inflação. In: Earp, F.S.; Bastian, E.F.; ModenisI, A.N.. (Org.). Como vai o Brasil? A economia brasileira no terceiro milênio. 1ed.Rio de Janeiro: Imã Editorial, v. 1, p. 1-279.

Modenesi, A.; Araújo, E.C. (2013). Price stability under inflation targeting in Brazil: an empirical 
analysis of the monetary policy transmission mechanism based on a VAR model (2000-2008). Investigación Económica, vol. LXXII, n. 283, p. 99-133.

Nassif, A; Feijó, C; Araújo, E. (2020). Macroeconomic Policies in Brazil before and after the 2008 Global Financial Crisis: Brazilian Policy-Makers Still Trapped in the New Macroeconomic Consensus Guidelines, Cambridge Journal of Economics, vol. 44, p. 749-779.

Oreiro, J. L; Lemos, B. P.; Padilha, R. A; Passos, M. (2009). O Regime de Metas de Inflação e a Governança da Política Monetária no Brasil: Análise e proposta de mudança in Oreiro, J. L; Paula, L F e Sobreira, R., Política monetária, bancos centrais e metas de inflação: teoria e experiência brasileira, Editora FGV.

Phillips, P. C. B. (1987). Time series regression with a unit root. Econometrica, v. 55, n. 2.

Resende, A. L. (2021). A quem interessa a alta dos juros, Valor Econômico, caderno Eu \&, 1/04/2021.

Sicsú, J. (2003). Políticas Não-Monetárias de Controle da Inflação: uma proposta pós-keynesiana. Análise Econômica, 21(1), Jan-Mar; p. 115-136.

Sicsú, J.; Oliveira, S. C. (2003). Taxa de juros e controle da Inflação no Brasil. In: Sicsú, J.; Oreiro, J.L.; Paula, L.F. (orgs.), Agenda Brasil: políticas econômicas para o crescimento com estabilidade de preços. Barueri: Editora Manole.

Sicsú, J; Modenesi, A; Pimentel, D. (2021) Severe recession with inflation: the case of Brazil, Journal of Post Keynesian Economics, v. 44, p. 89-111.

Sicsú, J. (2019) Brasil: É uma depressão, não foi apenas uma recessão, Revista de Economia Contemporânea, v. 23, p. 1-41, 2019.

Tily, G. ( 2012). Keynes's monetary theory of interest. In BIS papers no. 65, Threat of fiscal dominance?, http://www.bis.org/publ/bppdf/bispap65.pdf.

Yellen, J. (2016). Many targets, many instruments: where do we stand?, in Akerloff, G; Olivier, B; Romer, R e Stiglitz, J., What have we learned? Macroeconomic policy after the crisis, The MIT Press, Cambridge, Massachusetts, London, England. 